\title{
NÚMERO TOTAL DE ESPERMATOZÓIDES DE GARANHÕES OBTIDOS ATRAVÉS DA COLHEITA COM VAGINA ARTIFICIAL E POR FLUXO RETRÓGRADO DA CAUDA DO EPIDÍDIMO
}

\section{(Total number of spermatozooa from stud-horses collected by means of artificial vagina and through feedback flow of the epididymis tail)}

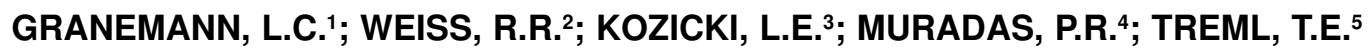 \\ 1Mestrando em Patologia Veterinária, Medicina Veterinária - UFPR, Curitiba - Paraná - Brasil. \\ Icgranemann@sulbbs.com; \\ ${ }^{2}$ Curso de Pós Graduação em Ciências Veterinárias - UFPR; \\ ${ }^{3}$ Curso de Pós Graduação - PUCPR; \\ ${ }^{4}$ Mestranda em Patologia Veterinária, Medicina Veterinária - UFPR; \\ ${ }^{5}$ Acadêmica de Graduação de Medicina Veterinária - UFPR.
}

\begin{abstract}
RESUMO - Neste trabalho foram utilizados 7 garanhões com o objetivo de se comparar o número total de espermatozóides recuperados através da técnica de fluxo retrógrado da cauda do epidídimo com os colhidos com a vagina artificial. Numa fase preliminar foi realizada avaliação do sêmen colhido com a vagina artificial e 7 dias após os garanhões foram submetidos ao procedimento de orquiectomia bilateral para recuperação e avaliação dos espermatozóides da cauda do epidídimo. As células espermáticas foram colhidas através da segmentação em 3 partes da cauda do epidídimo e sua lavagem por fluxo retrógrado com diluente. A contagem do número total de espermatozóides colhidos com a vagina artificial da cauda do epidídimo foi realizada imediatamente após a colheita. Concluiu-se que houve diferença significativa $(p<0,05)$ entre as duas técnicas utilizadas.
\end{abstract}

Palavras-chave: espermatozóides, garanhão, cauda do epidídimo.

\begin{abstract}
The aim of the present research work, carried out with 7 stud-horses, was to compare the total number of spermatozzoa recovered from the artificial vagina. In a preliminary phase, evaluation of the semen harvested with the artificial vagina was carried out. After 7 days of this procedure, the stallions underwent bilateral orchiectomy for recovery and evaluation of the epididymal tail spermatozooa. For the latter procedure, the spermatic cells had been harvested through the segmentation in 3 parts of the epididymal tail and its washing through a feedback flow with proper diluents. The counting of the total number of spermatozoa was carried out immediately after the procedures of their harvesting. It was concluded that there was a statistical difference $(p<0,05)$ between the two used techniques.
\end{abstract}

Key-words: spermatozoids, stallion, tail of the epididymis.

\section{Introdução}

Com o incremento da inseminação artificial em eqüinos e aperfeiçoamento dos processos de diluição, criopreservação e descongelamento do sêmen, na presença ou não do plasma seminal, é possível minimizar as perdas de material genético quando um animal for a óbito inesperadamente ou quando não for possível colher seu material genético in vivo, pelos métodos convencionais, é possível utilizar os espermatozóides epididimais.

O epidídimo, do Grego epi (dentro) e didymoi (germinativo ou testículo), é um órgão alongado, localizado na superfície do testículo, monotubular, enrolado em espiral, que transporta os espermatozóides dos vasos eferentes para os vasos deferentes (SULLIVAN et al., 2005).

A colheita de espermatozóides epididimais pode ser a última chance para assegurar a preservação do material genético após lesão ou morte do reprodutor. Estudos têm demonstrado que espermatozóides epididimais podem ser usados na inseminação artificial, fertilização in vitro e injeção intracitoplasmática de espermatozóides com resultados satisfatórios (JAMES et al., 2002; BRUEMMER et al. 2002; MORRIS et al. 2002; TIPLADY et al. 2002).

A primeira dificuldade na utilização dos espermatozóides epididimais é a obtenção dos mesmos da cauda do epidídimo. Muitos métodos de recuperação são descritos e variam dependendo do autor e da espécie animal. No caso dos pequenos animais devido ao tamanho do epidídimo, o método de preferência é através da flutuação, que consiste em cortar ou fatiar a cauda do epidídimo e deixar repousar em um meio gelatinoso. Desta maneira, os espermatozóides migram para o meio e são recuperados através de filtração (YU e LEIBO, 2002). Esta técnica também é usada para obter amostras de espermatozóides de grandes animais (HISHINUMA et al., 2003). Uma técnica similar consiste em fazer vários 
cortes na cauda do epidídimo e pressionar suavemente a cauda colhendo os espermatozóides por extravasamento (KAABI et al., 2003).

Outro método consiste em promover um fluxo retrógrado na cauda do epidídimo aplicando pressão nos vasos deferentes até que o conteúdo da cauda do epidídimo escorra através de um corte feito na junção com o corpo do epidídimo (GARDE et al., 1994). A pressão é gerada com uma seringa que injeta ar ou algum líquido não prejudicial aos espermatozóides (COMIZZOLI et al., 2001).

MARTINEZ-PASTOR et al. (2006), demonstraram que a colheita de espermatozóides da cauda do epidídimo através do fluxo retrógrado é a técnica mais indicada, pois as amostras obtidas são menos contaminadas e de melhor qualidade seminal em relação aos outros métodos. Possui a limitação de ser usada para grandes animais devido ao tamanho do epidídimo e ser mais complexa que as outras técnicas.

O objetivo deste trabalho foi colher espermatozóides da cauda do epidídimo de garanhões através de uma modificação da técnica de fluxo retrógrado, descrita por GARDE et al. (1994), e comparar o número total de espermatozóides recuperados a partir desta modificação com o número total de espermatozóides colhidos com a vagina artificial.

\section{Material e Métodos}

Foram utilizados 14 epidídimos de 7 garanhões, com idade entre 40-90 meses, de diferentes raças, oriundos de criatórios de Curitiba e Região Metropolitana. Dos 7 garanhões, dois eram poneis e dois tinham mais que 60 meses de idade. Os animais utilizados no experimento foram alojados no Hospital Veterinário da Universidade Federal do Paraná, em baias individuais e alimentados com concentrado comercial contendo $13 \%$ de proteína bruta, $10 \%$ de fibras totais, $1,5 \%$ de Ca e $0,5 \%$ de $\mathrm{P}$, feno de Coast Cross e água ad libitum durante todo o experimento.

A colheita de sêmen foi realizada semanalmente, com vagina artificial modelo Hannover, sendo realizada no mínimo duas colheitas de cada garanhão antes da orquiectomia.

A avaliação da concentração espermática $\left(\mathrm{mm}^{3}\right)$ foi realizada em câmara de Toma Nova, utilizando-se sêmen diluído na proporção de $0,05 \mathrm{~mL}$ de sêmen para $10 \mathrm{~mL}$ de solução formol salina a $1 \%$. O número total de espermatozóides no ejaculado foi obtido multiplicando-se a concentração espermática $\left(\mathrm{mm}^{3}\right)$ pelo volume de sêmen ejaculado.

Os epidídimos foram obtidos uma semana após a última colheita de sêmen utilizando-se a vagina artificial, quando os garanhões foram submetidos à orquiectomia bilateral.

A técnica de colheita dos espermatozóides da cauda do epidídimo foi realizada da seguinte maneira: o complexo testículo-epidídimo foi separado em duas partes: testículo e cauda do epidídimo, sendo feita uma lavagem da cauda do epidídimo com soro fisiológico pré-aquecido $\left(37^{\circ} \mathrm{C}\right)$, para remoção do sangue. O tecido conjuntivo que recobre a cauda do epidídimo foi removido por dissecação cuidadosamente para evitar o rompimento dos vasos sanguíneos e do ducto epididimário. Após a remoção dos tecidos, foram desfeitos os contornos do ducto epididimário, que formam a cauda do mesmo.

Em seguida, o ducto epididimário foi segmentado em três partes para facilitar a lavagem e a colheita dos espermatozóides, tendo cada segmento de 20 a 40 centímetros, dependendo do tamanho da cauda do epidídimo.

Para realização da lavagem, uma das extremidades do segmento foi pinçada, para evitar o extravasamento dos espermatozóides, mantendo o segmento estendido na posição vertical, sobre um filtro acoplado a um copo coletor pré-aquecido $\left(37^{\circ} \mathrm{C}\right)$, sendo o diluente injetado no lúmen do mesmo, com auxílio de uma seringa e agulha $(0,45 \times 13)$, imediatamente abaixo do local pinçado, fazendo com que os espermatozóides fossem carreados pelo diluente e recuperados na outra extremidade.

A lavagem foi feita com o diluente Botu-Crioß1, préaquecido a $37^{\circ} \mathrm{C}$. Para lavagem de cada cauda do epidídimo foram utilizados $10 \mathrm{~mL}$ de diluente, divididos entre os três segmentos. Após o término da lavagem, os espermatozóides recuperados da cauda do epidídimo (três segmentos misturados) foram submetidos ao mesmo processo a que foram submetidos os colhidos com a vagina artificial para contagem do número total de espermatozóides.

As diferenças das médias foram comparadas pelo teste de Tukey ao nível de 5\%.

\section{Resultados}

$\mathrm{Na}$ TABELA 1 observa-se que o número total de espermatozóides colhidos da cauda de apenas um dos epidídimos de um mesmo garanhão, foi superior ao número total de espermatozóides colhidos com a vagina artificial, com exceção do epidídimo direito do garanhão 6 , que apresentou número total de espermatozóides inferior ao da vagina artificial.

Ainda na TABELA 1 pode-se observar que dos 7 garanhões utilizados neste experimento, 6 obtiveram um número total de espermatozóides maior no epidídimo esquerdo e apenas um garanhão apresentou número total de espermatozóides maior no epidídimo direito. É possível verificar nesta tabela que existe uma grande variação entre os epidídimos esquerdo e direito do mesmo garanhão.

Igualmente observa-se que o somatório de espermatozóides recuperados do epidídimo esquerdo e direito dos garanhões foi muito superior ao número total de espermatozóides colhidos com a vagina artificial. 
Número total de espermatozóides de garanhões obtidos através da colheita com vagina artificial e por fluxo...

TABELA 1 - COMPARAÇÃO DO NÚMERO TOTAL DE ESPERMATOZÓIDES COLHIDOS COM A VAGINA ARTIFICIAL E ESPERMATOZÓIDES COLHIDOS DA CAUDA DOS EPIDÍDIMOS DOS GARANHÕES.

\begin{tabular}{ccccc}
\hline \multirow{2}{*}{ Garanhões } & \multicolumn{4}{c}{ Número Total de Espermatozóides $\times 10^{9}$} \\
\cline { 2 - 5 } & $\begin{array}{c}\text { Vagina } \\
\text { Artificial }\end{array}$ & $\begin{array}{c}\text { Epidídimo } \\
\text { Esquerdo }\end{array}$ & Epidídimo Direito & $\begin{array}{c}\text { Epidídimo Esquerdo + } \\
\text { Epidídimo Direito }\end{array}$ \\
\hline 1 & 5,1 & 17,1 & 11,7 & 28,8 \\
3 & 5,4 & 17,6 & 9,2 & 26,8 \\
4 & 31,9 & 55,5 & 57,6 & 113,1 \\
5 & 13,5 & 28 & 24 & 52 \\
6 & 14,5 & 19 & 16 & 35 \\
7 & 28 & 35,7 & 21,6 & 57,3 \\
\hline
\end{tabular}

A TABELA 2 apresenta a média do número total de espermatozóides de todos os garanhões colhidos com vagina artificial, epidídimos esquerdos, direitos e de ambos os epidídimos. Verifica-se que a média do número total de espermatozóides colhidos tanto na cauda dos epidídimos esquerdos quanto dos direitos foi significativamente $(p<0,05)$ superior a média dos colhidos com vagina artificial, e que a média do número total de espermatozóides dos epidídimos esquerdos apresentou-se significativamente superior $(p<0,05)$ a média dos epidídimos direitos.

A TABELA 2 demonstra que o número total de espermatozóides recuperados da cauda dos epidídimos esquerdo, direito e de ambos os epidídimos dos garanhões foi em média respectivamente: $1,72,1,35$ e 3,08 vezes superior ao número total médio de espermatozóides colhidos com a vagina artificial.

TABELA 2 - COMPARAÇÃO MÉDIA DO NÚMERO TOTAL DE ESPERMATOZÓIDES COLHIDOS COM VAGINA ARTIFICIAL E ESPERMATOZÓIDES COLHIDOS DA CAUDA DOS EPIDÍDIMOS DOS GARANHÕES.

\begin{tabular}{cccc}
\hline Grupos & $\mathrm{n}$ & $\begin{array}{c}\text { Média* do Número Total de } \\
\text { Espermatozóides x } 10^{9}\end{array}$ & Desvio Padrão x $10^{9}$ \\
\hline Vagina Artificial & 7 & $19,08 \mathrm{a}$ & 12,05 \\
Epidídimo Esquerdo & 7 & $32,88 \mathrm{~b}$ & 19,39 \\
Epidídimo Direito & 7 & $25,84 \mathrm{c}$ & 17,45 \\
$\begin{array}{c}\text { Epidídimo Esquerdo }+ \\
\text { Direito }\end{array}$ & 14 & $58,72 \mathrm{~d}$ & 34,23 \\
\hline
\end{tabular}

a, b, c, d = Há diferença estatística entre cada variável.

AFIGURA 1 representa a comparação média do número total de espermatozóides colhidos com vagina artificial dos 7 garanhões, dos 7 epidídimos esquerdos e direitos e a média de todos os epidídimos. 
FIGURA 1 - COMPARAÇÃO DA MÉDIA DO NÚMERO TOTAL DE ESPERMATOZÓIDES COLHIDOS COM A VAGINA ARTIFICIAL E DA CAUDA DOS EPIDÍDIMOS DOS GARANHÕES.

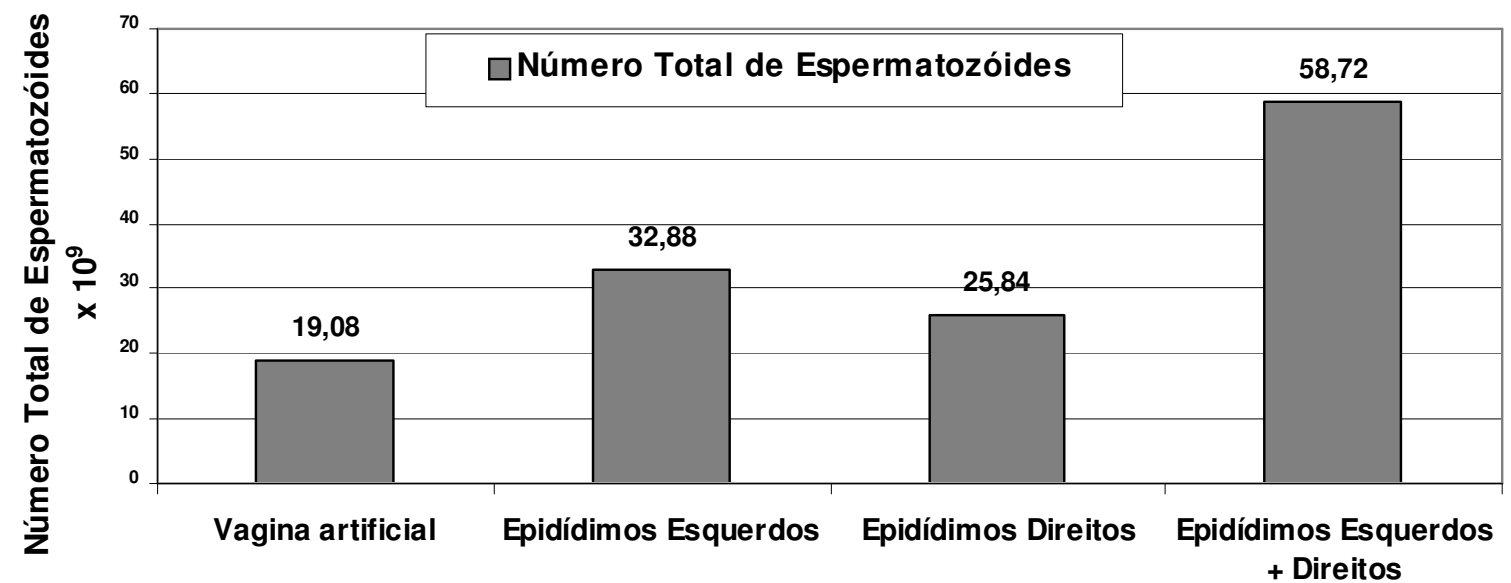

A FIGURA 2 representa a comparação média dos epidídimos esquerdos e direitos dos do número total de espermatozóides colhidos garanhões.

FIGURA 2 - COMPARAÇÃO ENTRE O NÚMERO TOTAL MÉDIO DE ESPERMATOZÓIDES COLHIDOS DA CAUDA DOS EPIDÍDIMOS ESQUERDOS E DIREITOS DOS GARANHÕES.

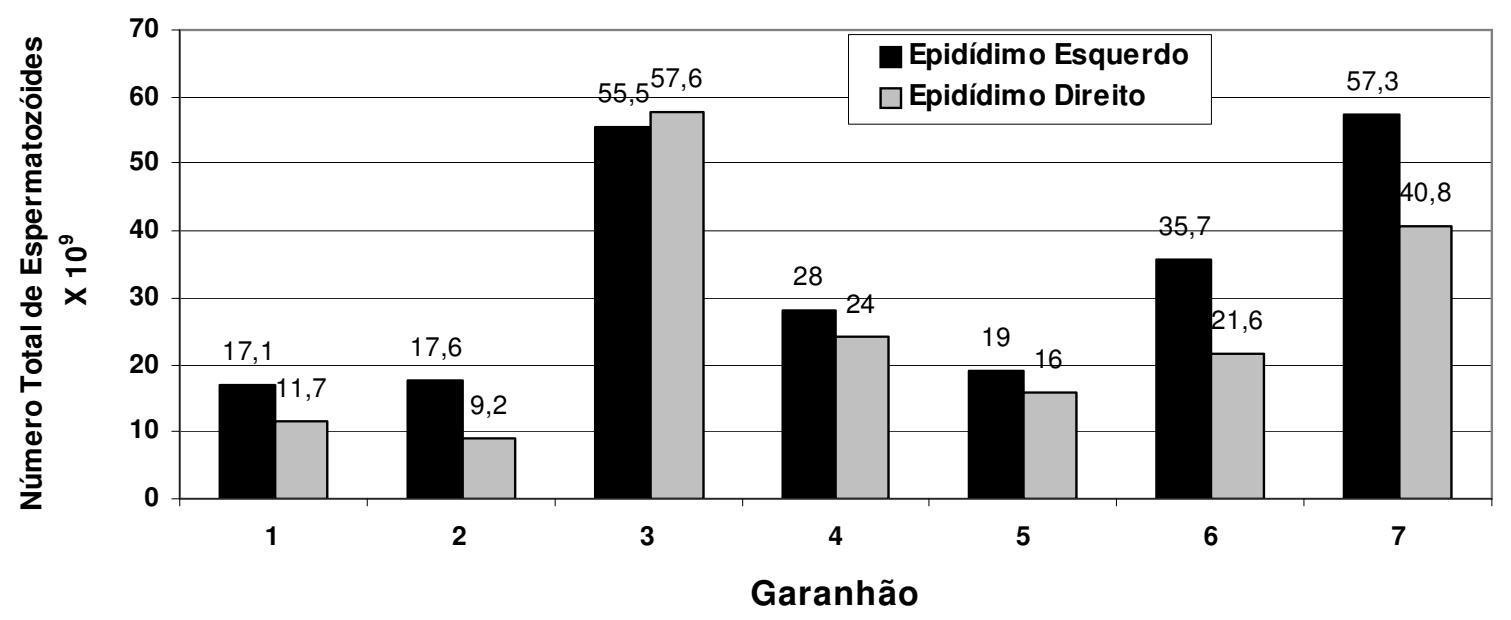

\section{Discussão}

O número total de espermatozóides colhidos da cauda do epidídimo de garanhões, através da técnica de fluxo retrógrado, foi significativamente $(p<0,05)$ superior aos encontrados no sêmen colhido com a vagina artificial, justificando que a cauda do epidídimo possui função de armazenamento, sendo liberados em cada ejaculação uma parcela dos espermatozóides epididimais (JOHNSON et al., 2000; SULLIVAN et al., 2005). Os espermatozóides obtidos da cauda do epidídimo não estão diluídos com as secreções liberadas durante a ejaculação, fato este, que justifica o elevado número de espermatozóides (AMANN, 1993).
A segmentação da cauda do epidídimo facilitou a lavagem do mesmo, sendo que alguns ductos epididimários eram muito longos e sua parte final apresentava lúmen reduzido. As amostras obtidas foram quanti-qualitativamente satisfatórias, corroborando com os relatos de MARTINEZPASTOR et al. (2006).

A avaliação do número total de espermatozóides colhidos da cauda do epidídimo corrobora os valores relatados por BEDFORD (1994), ao observar que, dependendo do tamanho da cauda do epidídimo e idade, um garanhão pode armazenar na cauda do epidídimo espermatozóides suficientes para vários ejaculados consecutivos, justificando os garanhões 2 e 3 terem possuírem número de espermatozóides, 
Número total de espermatozóides de garanhões obtidos através da colheita com vagina artificial e por fluxo...

pelo seu tamanho (pôneis). Os garanhões que obtiveram maior diferença entre o número total de espermatozóides colhidos da cauda do epidídimo e com a vagina artificial, tinham a cauda do epidídimo maior em função da idade, pois tinham mais de 60 meses.

GARDE et al. (1998) relataram diferenças importantes na quantidade de espermatozóides entre epidídimos de um mesmo indivíduo, corroborando os valores encontrados neste experimento.

\section{Conclusão}

Com base nos resultados obtidos neste experimento concluiu-se que: a colheita de espermatozóides da cauda do epidídimo através da modificação da técnica de fluxo retrógrado, pôde ser realizada de maneira rápida e eficiente; o número total de espermatozóides colhidos da cauda dos epidídimos esquerdo e direito dos garanhões foi significativamente superior ao número total de espermatozóides colhidos com a vagina artificial; o número total médio de espermatozóides dos epidídimos esquerdos foi significativamente superior aos direitos.

\section{Referências}

AMANN, R.P. Physiology and endocrinology. Equine Reproduction, p.658-673, 1993.

BEDFORD, J.M. The status and the state of the human epididymis. Human Reproduction, v.9, p.2187-2199, 1994.

BRUEMMER, J.E.; REGER, H.; ZIBINSKI, G.; SQUIRES, E.L. Effect of storage at $5^{\circ} \mathrm{C}$ on the motility and cryopreservation of stallion epididymal spermatozoa. Theriogenology, v.58, p.405-407, 2002.

COMIZZOLI, P.; MERMILLOD, P.; COGNIE, Y.; CHAI, N.; LEGENDRE, X.; MAUGE, R.; Succesful in vitro production of embryos in the red deer (Cervus elaphus) and the sika deer (Cervus nippon). Theriogenology, v.55, p.649-659, 2001.

GARDE, J.; AGUADO, M.; PEREZ, S.; GARRIDO, D.; PEREZ-GUZMAN, M.; MONTORO, V. Physiological characteristics of epididymal spermatozoa from postmorten rams. Theriogenology, v.41, p.2003, 1994.
GARDE, J.; ORTIZ, N.; GARCIA, A.; GALLEGO, L.; LANDETE, C.T.; LOPEZ, A. Post-morten assessment of sperm characteristics of the red deer during the breeding season. Archives of Andrology, v.41, p.195202, 1998.

HISHINUMA, M.; SUZUKI, K.; SEKINE, J. Recovery and cryopreservation of sika deer (cervus nippon) spermatozoa from epididymides stored at $4 \stackrel{\circ}{\mathrm{C}}$. Theriogenology, v. 59 , p. 813-820, 2003.

JAMES, A.N.; GREEN, H.; HOFFMAN, S.; LANDRY, A.M.; PACCAMONTI, D.; GODKE, R.A. Preservation of equine sperm stored in the epididymis at $4{ }^{\circ} \mathrm{C}$ for $24,48,72$ and 96 hours. Theriogenology, v.58, p.401404, 2002.

JOHNSON, L.; VARNER, D.D.; ROBERTS, M.E.; SMITH, T.L.; KEILLOR, G.E.; SCRUTCHFIELD, W.L. Efficiency of spermatogenesis: a comparative approach. Theriogenology, v.60, p.471-480, 2000.

KAABI, M.; PAZ, P.; ALVAREZ, M.; ANEL, E.; BOIXO, J.C.; ROUISSI, H.; HERRAEZ, P.; ANEL, L. Effect of epididymis handling conditions on the quality of ram spermatozoa recovered post-mortem. Theriogenology, v.60, p.1249-1259, 2003.

MARTINEZ-PASTOR, F.; MACIAS, V.G.; ALVAREZ, M.; CHAMORRO, C.; HERRAEZ, P.; PAZ, P.; ANEL, L. Comparison of two methods for obtaining spermatozoa from the cauda epidydimis of Iberian red deer. Theriogenology, v.65, p.471-485, 2006.

MORRIS, L.; TIPLADY, C.; ALLEN, W.R. The in vivo fertility of cauda epididymal spermatozoa in the horse. Theriogenology, v.58, p.643-646, 2002.

SULLIVAN, R.; SAEZ, F.; GIROUARD, J.; FRENETTE, G. Role of exosomes in sperm maturation during the transit along the male reproductive tract. Blood Cells, Molecules, \& Diseases, v.35, p.1-10, 2005.

TIPLADY, C.A.; MORRIS, L.H.A.; ALLEN, W.R. Stallion epididymal spermatozoa: pre-freeze and post-thaw motility and viability after three treatments. Theriogenology, v.58, p.225-228, 2002.

YU, I.; LEIBO, S. Recovery of motile, membrane-intact spermatozoa from canine epididymides stored for 8 days at $4 \stackrel{\circ}{\circ}$. Theriogenology, v.57, p.1179-1190, 2002.

Recebido para publicação:

$20 / 04 / 2006$

Aprovado: 